\title{
SCOPING THE POTENTIAL ROLE OF THE WATER SECTOR IN URBAN GREENING AND COOLING: A CASE STUDY OF MELBOURNE
}

\author{
CASEY FURLONG ${ }^{1}$, KATH PHELAN $^{1}$, JAGO DODSON ${ }^{1}$ \& ROBERT CONSIDINE ${ }^{2}$ \\ ${ }^{1}$ Centre for Urban Research, RMIT University, Australia \\ ${ }^{2}$ Melbourne Water Corporation, Australia
}

\begin{abstract}
Climate change, urban densification and loss of green space are making cities hotter and less pleasant places in which to live. In some developed countries, heat waves now cause more deaths than any other natural disaster, and lack of green space is linked to decreased mental and physical health. Increasing green space, tree canopy cover, water bodies and irrigation can significantly cool urban environments, and positively influence physical and mental health, as well as biodiversity. Across the world, urban greening and cooling are primarily considered to be the functions of local government (municipalities). However, we hypothesise that the urban water sector (water utilities and waterway managers) has an existing role in urban greening which has significant potential to expand. This study makes use of a wide-ranging industry consultation process with 37 experts from 14 organisations within Melbourne, to (a) understand the current urban greening situation, (b) identify the gaps in current system, (c) investigate the current contribution of the water sector towards greening, and (d) scope out the potential for a larger role. Preliminary findings show that Melbourne's water sector is, in a number of ways, actively pursuing urban greening and cooling outcomes, and that more can be achieved when they work collaboratively with local government actions, rather than acting independently. The major areas through which Melbourne's water sector can further impact greening and cooling are found to be: (1) assisting in large scale planning of greening/cooling initiatives, in coordination with stormwater management and conservation of waterways; (2) statutory powers and informal guidance to influence new developments; (3) finance raising and financial evaluation capabilities to provide and justify funding; (4) credibility and social license to support municipalities in lobbying state government and other stakeholders; and (5) additional water for irrigation through alternative water source projects.

Keywords: urban water, water management, urban governance, liveability, urban greening, urban cooling, Integrated Urban Water Management, Water Sensitive Urban Design, green infrastructure.
\end{abstract}

\section{INTRODUCTION}

\subsection{Challenges of urbanisation}

The proportion of humanity that lives within cities is continually increasing. Between 1982 and 2015 the proportion of humanity living in cities increased from $40 \%$ to $54 \%$, while the total number of people living in cities increased from 1.8 billion to 3.9 billion [1]. Such an increase in urban populations creates many challenges for public authorities who manage cities, particularly in relation to the provision of physical infrastructures such as transport, housing, and water services, while maintaining a healthy environment and public health [2], [3].

Urban infrastructure contexts are significantly different in the developed world in comparison to the developing world. This difference is most easily described in terms of the current level of infrastructure deficit: the gap between the amount of infrastructure currently required and what currently exists. In the developing world, cities often have a substantial level of infrastructure deficit, such as an absence of sufficient transport, housing, water supply, sewerage and drainage assets. Areas which already have an infrastructure deficit are 
particularly vulnerable to changes in population and climatic conditions, and public initiatives within these cities are largely focused on reducing this level of infrastructure deficit [4].

In general, developed countries such as Australia currently have (at least approximately) the level of hard infrastructure required to service their existing populations and climatic conditions [5]. As a result of this, the urban policy discourse within developed countries typically focuses on not only what makes an area possible to live in (essential services such as electricity, water, sewerage), but also what makes an area pleasant and healthy to live in [6], such as open space, trees and vegetation [7].

Urbanisation has caused extensive damage to urban biodiversity and ecosystem services. Urban areas are increasingly impervious, have reduced groundwater recharge, increased flooding, and damaged urban waterways [8]. Biodiversity loss, which is a global phenomenon, is particularly visible in cities [9]. Tree loss, associated both with geographical expansion of cities as well as densification within cities, limits residents' connection to nature, and the related physical and mental health benefits [10]. Together with an increase in vehicle numbers, this results in degraded air quality [11]. Additionally, impervious surfaces such as roads, contribute to the "heat island effect" where urban areas may be as much as $10^{\circ} \mathrm{C}$ hotter than surrounding rural areas [12]. Such damage is compounded by climate change, which is predicted to increase surface temperatures by $2-4^{\circ} \mathrm{C}$ by 2100 [13].

These environmental and physical changes result in negative impacts on human health and wellbeing. Degraded waterways reduce a population's likelihood to walk and cycle, as well as sense of place and pride. Poor biodiversity limits a community's opportunities for connections to nature, which has an impact on mental health. Degraded air quality can contribute to reduced life expectancy [6], [10]. In urban areas of some developing countries such as Australia, heatwaves, which are exacerbated by urbanisation and a lack of trees, kill more people than any other natural disaster [14].

\subsection{Urban greening to protect human and environmental health}

For all of these reasons, urban authorities in developed countries are increasingly interested in urban greening as a policy response to the damaging impacts of urbanisation and climate change. The trend towards recognising these benefits is correlated with the idea of "Green Infrastructure", which implies that the natural assets within a city provide an essential service, similar to water infrastructure, roads, electricity and telecommunications networks [15].

Urban greening refers to protecting and increasing the number of trees within a city (on both public and private land) as well as the level of public green space such as parks, and various other more recent initiatives such as green roofs and walls. Urban greening can significantly ameliorate the environmental and health challenges associated with urbanisation through: reducing temperatures in urban areas, providing habitat for biodiversity, increasing exercise, improving air quality, positively impact on a communities' mental and social outcomes [16].

Fig. 1 gives a summary of some of the major benefits of urban greening, which can be delineated into environmental benefits, physical health benefits and mental health benefits.

Generally urban greening is considered to be the responsibility of local government (municipalities). Municipalities do both on-the-ground works, such as tree planting and maintenance in streets and parks, as well as planning where new planting should occur and regulating development to minimise tree loss on private land. National and state governments also have important roles in urban greening through policies which guide local 


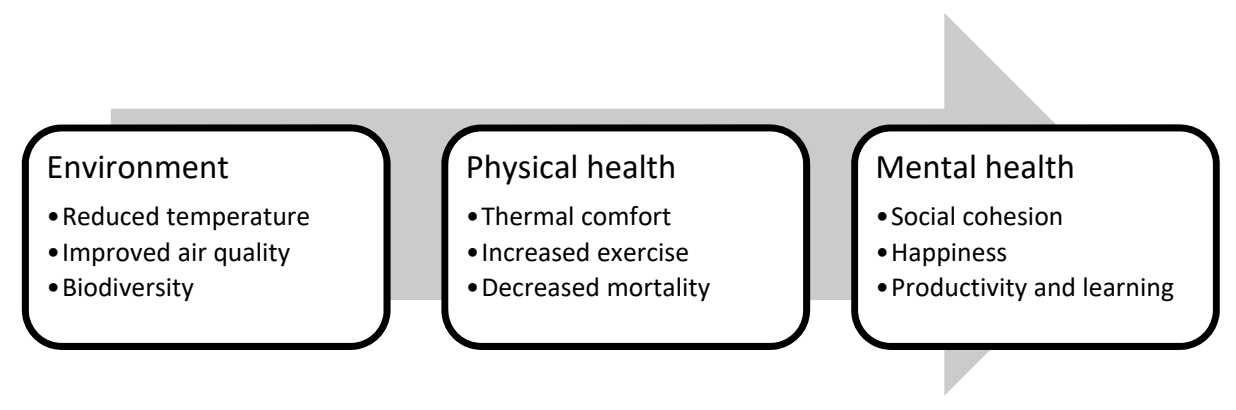

Figure 1: Liveability benefits of urban greening. (Based on Kendal et al., 2016 [16].)

government practices, such as overarching planning schemes, and financial subsidies and grants for particular projects. The wider community also influences urban greening through landscaping private gardens, nature strips outside houses, and in some cases conservation volunteering for public land greening (such as "friends of" groups) [17].

\subsection{Scoping the role of the urban water sector in urban greening and cooling}

The mandate of public water utilities has evolved over time to meet the challenges and needs of urban settlements. When initially created by governments, water utilities focused on the storage and transfer of clean water into cities. Later, the challenge shifted to removing dirty water from cities through sewerage and drainage systems. From the 1960s onwards, across the world, water utilities have increasingly concentrated on environmental protection of waterways and bays. This began with upgrading sewage treatment plants, and in some locations constructed wetlands and biofiltration devices aimed to treat and retain urban stormwater [18]. From the 1990s many countries' water utilities have emphasised water security as populations have continued to increase but the total capacity of dams and rivers has largely either remained the same, or reduced due to climate change and pollution [19]. Water utilities have thus looked towards alternative water supply options such as desalination and wastewater and stormwater reuse [20]. In many areas water utilities have adopted the concept of liveability, particularly in relation urban greening's potential to provide multiple environmental and social benefits, as shown above in Fig. 1 [21].

A number of philosophies have been developed that relate to how water utilities can effectively integrate their core functions of water supply, sewerage and drainage services together with environmental protection, water security and liveability. In the Australian context, the most popular terms have been Integrated Urban Water Management and Water Sensitive Urban Design [22]. In terms of physical infrastructure these two terns are associated with water reuse and stormwater management, to minimise the import of potable water, and the export of stormwater and wastewater, into and out of urban areas of various scales [23]. Stormwater management projects such as wetlands and biofiltration (raingardens and swales) contribute to urban greening, and water reuse projects provide additional water to assist in urban greening during times of water scarcity. However, these philosophies fall short of providing a framework for understanding the potential broader role that water utilities could play in the urban greening agenda.

The current paper begins to scope out that potential role for water utilities in urban greening, through a case study of Melbourne, Australia. Melbourne is widely recognised as a leader in urban water management [24], and is therefore well-suited to evaluate in relation 
to progressive actions within the water sector. The funding organisation for this research also has a particular interest in this city.

In order to investigate this topic the authors have conducted a wide-ranging industry consultation to discuss the role that Melbourne's water sector currently has in relation to urban greening, and scope out other areas where additional contributions could be made. This consultation has involved semi-structured interviews with 37 experts from 13 organisations in order to discuss broad water utility and municipality operations that relate to urban greening, and also enable the identification of specific projects and initiatives.

The remainder of this paper summarises and discusses the findings from the consultation process, and uses these findings to scope out a possible role for water utilities in the broader urban greening agenda. Some of these findings are specifically relevant to Melbourne, but many are likely to be relevant across the developed world, as will be discussed in the conclusion.

\section{EXPLORING THE POTENTIAL ROLE OF WATER UTILITIES IN GREENING/COOLING (MELBOURNE CASE STUDY)}

\subsection{Urban greening in Melbourne}

As is typical across the world, in Melbourne urban greening is primarily the responsibility of municipalities. Metropolitan Melbourne has 31 municipalities (or more, depending on how it is defined; see Fig. 2) with varying socioeconomic and biophysical circumstances. In general, central and inner-eastern Melbourne is more affluent and greener. By comparison, Melbourne's western suburbs have less rainfall, fewer trees, poorer soils, and poorer mental and physical health [25]. Recent research suggests that tree canopy cover increases, almost in a linear manner, from the western municipalities of Melbourne (e.g. Wyndham at 3.1\% cover), to the centre (e.g. City of Melbourne at $12.9 \%$ cover), to the north eastern (e.g. Yarra Ranges at $77.2 \%$ cover) [26].

Municipalities in Melbourne plant, water and maintain trees and vegetation in public streets and parks. They produce street tree plans to guide tree planting location and replacement. In general, they also undertake community engagement activities to encourage greening. Six of Melbourne's municipalities have produced "Urban Forest Strategies" which attempt to consider urban greening from a holistic perspective to protect and increase their urban forests and identify appropriate implementation mechanisms. For example, two municipalities have amended their residential development regulation controls (approval processes for building new homes) to require developers to retain and/or plant trees in private gardens in the front and back of properties [17].

\subsection{Evaluation of current system}

From the industry consultation process, it has been found that municipalities are becoming increasingly aware of the many health and biodiversity benefits urban greening can provide. However, the process also identified a number of factors which contribute to making urban greening within Melbourne a very challenging task.

Regional coordination of urban greening, such as the creation of green corridors, is difficult due to the lack of State government leadership and the fragmented nature of Melbourne's 31 municipalities. This lack of coordination contributes to reinforcing inequality, as affluent areas continue to benefit from the positive mental and physical health 


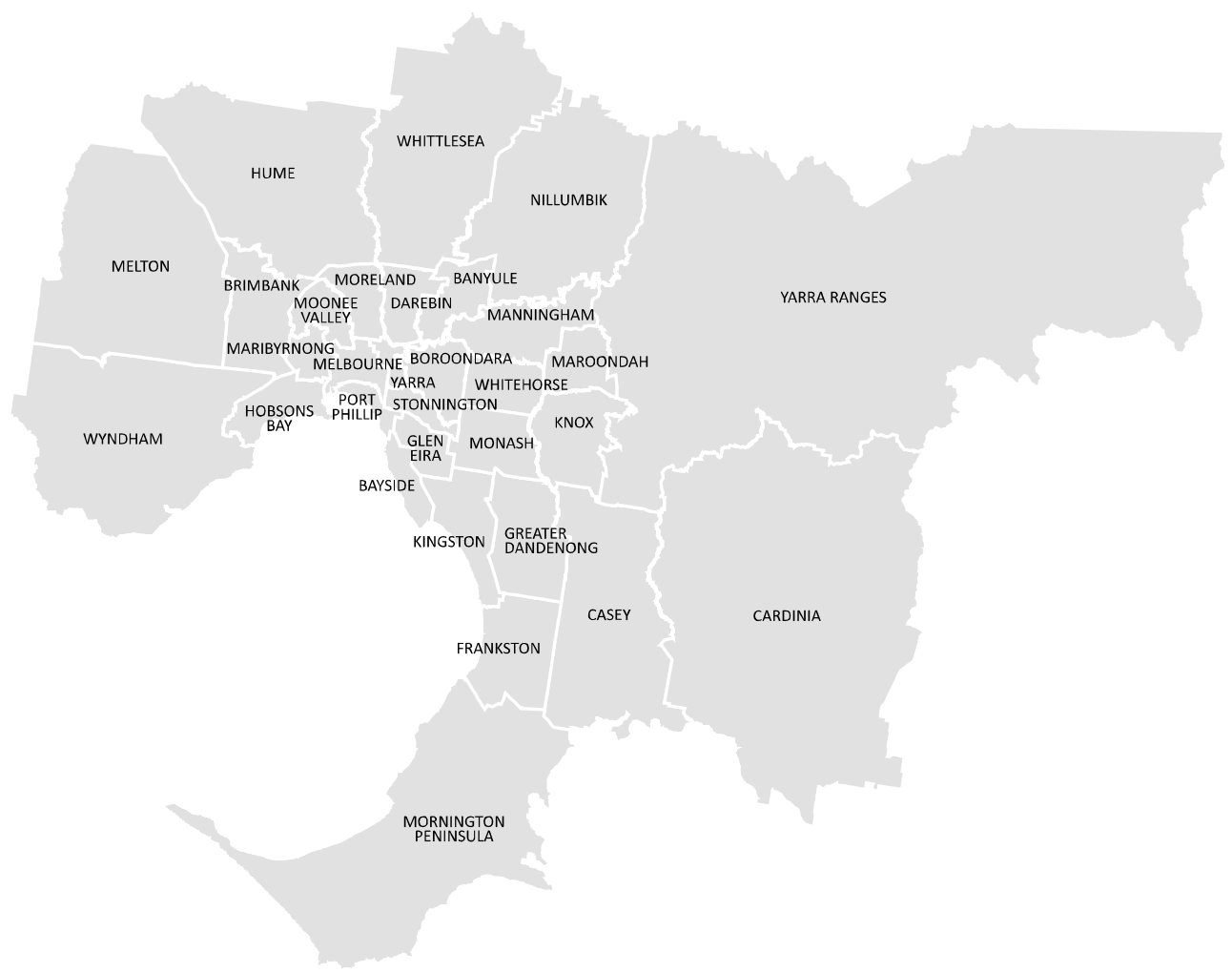

Figure 2: Metropolitan Melbourne's 31 municipalities (sometimes more are added).

outcomes associated with greater canopy cover, while lower socioeconomic areas do not. Municipalities are further constrained by State government "rate capping" which prevents local governments from increasing their (property-value based) charges to residents above the rate of inflation. This limits the amount of revenue that these institutions can collect from their residents, and therefore reduces the amount of funding available for urban greening.

While local governments are increasingly recognising the benefits of greening, a number of consulted experts noted significant pockets of resistance to urban greening. Experts refer to individual teams and professions which view greening as a problem rather than a solution. Specific issues included risks of trees damaging electricity wires, car crashes, and damage to roads and properties. Municipal recreation and leisure teams may consider trees as interfering with sport and exercise. Vegetation can also pose perceived safety risks, particularly for females walking through parks at night, because it is possible for a person to hide from sight. Another example described a municipality's environmental team expressing concern that tree planting and landscaping within a reserve may have a negative impact on local lizards, by blocking the sun and their movement paths.

Due to this lack of agreement with particular stakeholders, there are some interesting examples of practical barriers to the urban greening agenda. Firstly, regulations for electricity wire clearance distances developed as a result of a Royal Commission into the 2009 Victorian bushfires prevent local governments from planting large trees in many streets, despite most of urban Melbourne facing no bushfire risk. Secondly, insurance companies have influenced 
the state road authority's creation of "clear zone" regulations which make roadside tree planting difficult, particularly on $80 \mathrm{~km} /$ hour or higher speed limit roads. Thirdly, new developments on the fringes of the city have mandated minimum open space area requirements, but no equivalent minimum requirements exist for public trees (in streets and parks), or for space to be reserved for trees in private gardens.

A major investigation, known as the Resilient Melbourne Strategy, has provided additional evidence that there is currently a significant problem for urban greening in Melbourne. In 2013, the Rockefeller Foundation began a global initiative named 100 Resilient Cities. Melbourne was one of the cities included in the first round of the selection process, and received funding to employ a Chief Resilience Officer for two years, and access to a variety of other in-kind resources. Between 2014 and 2016 the Resilient Melbourne group, hosted within the City of Melbourne, collaborated with 29 of Melbourne's 31 municipalities to produce the Resilient Melbourne Strategy. This strategy determined that urban greening was the highest priority resilience area for Melbourne, and has proposed a Metropolitan Melbourne scale Urban Forest Strategy, which is currently in its early phases [27].

In summary, Melbourne's urban greening in public streets and parks is likely to remain relatively stable, but the level of greening in private gardens will continue to decrease over time as urbanisation continues. This is a major problem because research suggests that the majority of trees exist on privately owned land [28]. Additional efforts are therefore needed to increase the level of greening on public land, and limit the reduction of greening on private land to prevent damaging impacts on public health and biodiversity. Therefore, beginning to explore how the water sector can collaborate with municipalities to achieve greening has become a relevant issue. The remainder of the paper considers the possible role for the water sector in strategic interventions to promote greening.

\subsection{Existing efforts by Melbourne's water sector towards greening and cooling}

This section describes the current role of Melbourne's water sector in the urban greening agenda. Water infrastructure in Metropolitan Melbourne is predominantly managed by four institutions. Melbourne Water is the bulk water, sewerage and drainage provider (they manage the dams, and the large sewerage treatment plants and drainage pipes), as well as the waterways authority. City West Water, Yarra Valley Water and South East Water are the customer interfaces for the water supply and sewerage systems, managing the reticulation and collection systems which connect houses to dams and sewerage treatment plants [23].

Currently Melbourne's water sector is unclear about its overall role in the broader urban greening agenda. However, the industry consultation revealed a number of areas in which the water sector is already impacting on urban greening, including: vegetated stormwater and flooding infrastructure; planting along waterway corridors; re-naturalisation of concreted channels; landscaping of decommissioned assets; and establishment of the Greening the West group. Each of these will now be briefly described.

The water sector currently influences urban greening through providing vegetated stormwater and flood management infrastructure. Historically urban stormwater and flood management infrastructure was made up of pipes, retarding basins and concreted channels. More recently a significant proportion of these assets include vegetated wetlands, biofiltration systems and swales. These are generally referred to as Water Sensitive Urban Design elements, Sustainable Urban Drainage Systems, or "Green Infrastructure" (although this can generate confusion about the meaning of the term in comparison to the earlier description) [22]. Melbourne's water sector contributes to urban greening through vegetated 
stormwater assets via two major mechanisms. The first is through planning controls which require new developments to include stormwater management assets (funded by developers). The second is through providing financial grants to municipalities to construct stormwater assets in existing suburbs. However, at present design of these stormwater assets does not explicitly consider shade for urban cooling, community recreation or biodiversity considerations, and generally they are not co-located with parks to create green corridors.

Separate to providing stormwater flooding infrastructure, the water sector also directly protects and enhances urban waterways. On natural waterways, Melbourne Water conducts tree and vegetation planting to stabilise river banks and improve water quality. However, over the past 100 years, water authorities transformed many natural waterways into concreted channels, to transfer stormwater out of the city faster. Now Melbourne's water sector is actively pursuing an agenda of returning concrete channels back into natural waterways. This process is expensive, but creates significant liveability, greening and cooling benefits. In Melbourne, the naturalisation of Stony Creek is the most well-known of these projects. This project is located in Melbourne's western suburbs, which as explained earlier, has a deficit in trees and green space, and is thus an example of a targeted greening and cooling intervention by the water sector.

In a related project, Melbourne Water and City West Water are currently investigating the feasibility of transforming a decommissioned $27 \mathrm{~km}$ sewerage transfer asset into a linear park and bike-bath connecting the western suburbs to the Central Business District. Although such a project is so expensive that the water sector would require external funding contributions in order to undertake it.

Also, through the design and construction of wastewater and stormwater reuse projects, the water sector provides an alternative water source which is available during times of drought and water scarcity. Currently it is common practice for Melbourne's water utilities to equip new developments with a source of reuse water which is plumbed into houses, businesses and parks, for gardening purposes and some indoor uses such as toilets and laundry.

Finally, in possibly a world's first, in 2011 City West Water established a multiorganisational committee named Greening the West. This committee has 22 partner organisations including all of Melbourne's western municipalities, community groups, state government departments, and a number of other public organisations such as VicRoads (roads authority) and Parks Victoria (manager of large parks, reserves and forests). This group has a broad scope, including government and developer advocacy, joint funding submissions, capacity building and community engagement. One of its most significant outcomes has been providing local government urban greening advocates with a stronger argument to bring to senior bureaucrats and Councillors. Due to the diverse capability of the committee, in 2014 the Australian government awarded the group \$5 million in funding. Greening the West was then able to leverage this funding to plant 1 million trees in Melbourne's west. Interviewees acknowledged that without City West Water taking the initiative in this space, which involved creating the concept, and allocating two full time staff to the group, this significant outcome would have been impossible. It is an excellent example of the role the water sector in Melbourne can play in urban greening.

\subsection{Potential further role for Melbourne's water sector in urban greening}

As detailed above, Melbourne's water sector already has a significant role in the urban greening agenda. However, through the industry consultation that has been conducted, the 
researchers have begun to scope out a potentially expanded role in the urban greening agenda. A list of key opportunities which have been identified will be given here.

Firstly, as highlighted by Greening the West, there is an opportunity for the water sector to take on a more substantial coordination role. There are 31 different municipalities within Melbourne, and there is no agency that currently creates urban greening strategies at a larger scale. Without such a larger strategic process, it is difficult to plan for the creation of green corridors, which provide additional social and environmental benefits, and also difficult to deal with entrenched inequality between Melbourne's west and east. The Resilient Melbourne Strategy has identified the need for a city-wide strategy, and put forward a model for achieving this together with an international non-profit named The Nature Conservancy. Significant participation from the water sector in this initiative could prove extremely valuable, particularly in relation to linking the broader urban greening agenda to the development of vegetated stormwater and flood management infrastructure, as well as the restoration of urban waterways and their riverbanks. For example, vegetated wetlands, bio-filters and swales could be reimagined in order to produce more significant shade, cooling, recreation and biodiversity benefits. Also they could be specifically located in alignment with parks to create green corridors with walking and cycling trails, which provide biodiversity benefits and promote exercise.

Secondly, it has been found that the water sector has substantial influence, both through formal controls and informal influence, on the development of new infill (urban densification) and greenfield (geographical expansion of the city) developments around Melbourne. Through these channels there is significant opportunity for regulations that increase requirements for green space and tree canopy. In addition to increasing the overall level of greening within a development, as stated above, the water sector has the potential to help coordinate the locations of recreational parks, stormwater and flooding infrastructure, and waterways.

Thirdly, through direct investment and expertise in infrastructure business case development, the water sector can continue to directly invest in targeted greening and cooling focused projects. Key examples of this include the Stony Creek project, and the opportunity for a linear park along a decommissioned sewerage asset, which have both been mentioned in the previous section. At present the Stony Creek project is fully funded, and proceeding, however the far larger linear parkland project is proceeding as a $100 \mathrm{~m}$ pilot project. A number of consulted experts have noted that the water sector may have a role in encouraging private sector participation in order to achieve the entire $27 \mathrm{~km}$ linear park concept. In addition, Melbourne Water is currently considering tree planting opportunities as part of an "urban cooling program".

Fourth, it has been noted by the consulted experts that due to Melbourne's water utilities being large, engineering-based organisations, they may be better placed to persuade Melbourne's road and electricity agencies towards relaxing regulations that inhibit street trees. One expert described water utilities as having a "unique social governance position", due to their size and level of community and government trust. There is a perception that it is easier for water utilities to make requests of other state government agencies than it is for Melbourne's municipalities, and therefore there may be significant value produced from water utilities actively pursuing such an advocacy role.

Finally, the water sector could potentially increase assistance to municipalities in designing and building alternative water source projects. The Resilient Melbourne Strategy has identified "Integrated Water Management", as the second highest priority area after the development of a city scale urban greening strategy. Many municipalities have already begun to plan their own small scale stormwater reuse projects [23], although Resilient Melbourne 
has determined that there are significant knowledge gaps, and begun developing some tools to assist with this matter. There is substantial opportunity for the water sector to take a significant role in this capacity building exercise.

\section{DISCUSSION AND CONCLUSION}

Although urban greening is largely considered to be a function of municipalities, and not within the jurisdiction of water utilities, the current paper finds that there are many ways in which water utilities do have an influence on urban greening. This role is especially present when there are close links between urban waterway management authorities, and water supply, sewerage and drainage utilities. In the case of Melbourne, the existence of Melbourne Water which combines all these functions creates a major opportunity for coordination of water management and urban greening functions. Collectively Melbourne's water sector has been found to have an existing role in urban greening which includes the following: (1) provision of vegetated stormwater and flooding management infrastructure, (2) planting along waterway corridors and re-naturalisation of concreted channels, (3) landscaping of decommissioned assets into linear parks, (4) provision of reuse water for irrigation, and (5) establishment of the Greening the West group to advocate and facilitate greening in Melbourne's west where there is currently a major deficit.

The water sector could expand its role in the wider urban greening agenda in the following ways: (1) participation in large (likely metropolitan-wide) scale planning of greening/cooling initiatives, in coordination with stormwater infrastructure and waterway conservation planning, (2) making use of statutory powers and informal guidance to influence new developments to have additional trees and green space, (3) finance raising and financial evaluation capabilities to provide and justify funding for greening and cooling focused projects, (4) making use of public trust and social license to support municipalities in lobbying state government agencies and other stakeholders towards changing regulations around tree clearances required for roads and electricity wires, and (5) assisting municipalities with "Integrated Water Management", such as designing and building small scale stormwater harvesting schemes to create alternative water sources.

It is important to note that urban governance responsibilities for water and urban greening are divided differently across the world. A large justification for an increased water sector role in urban greening in Melbourne is due to the fragmentation of municipal powers into 31 independent organisations, and a consolidation of water responsibilities largely into only four. In other cities, with a widely different urban governance structure, it is likely that many of the findings included in this paper would not be directly relevant. Although a number of these findings would likely be relevant to all developed cities around the world regardless of their urban governance structure:

- Planning of stormwater management/flooding infrastructure should be coordinated with public open space and urban forest strategies to create multiple benefits.

- Naturalisation of previously concreted channels, and landscaping of decommissioned assets can create opportunities for green space in highly urbanised areas.

- Planning/development controls can be used to increase greening without public funding.

- Public authorities of various types need to work together to influence governments towards changing unnecessary or excessive regulations (such as tree clearances around roads). 
In conclusion it is found that, across the developed world, there is sufficient justification for urban water utilities and waterways managers to consider their functions in relation to the broader urban greening agenda, and seek to collaborate with other public authorities to achieve urban cooling, public health, and the preservation of biodiversity.

\section{ACKNOWLEDGEMENTS}

The authors wish to thank the 37 experts who kindly gave up their valuable time to talk to us. The names of the organisations consulted include: Brimbank City Council, Cooperative Research Centre for Water Sensitive Cities, City West Water, Department of Environment, Land, Water and Planning, LeadWest, Loci, Melbourne Water, Monash University, Port Phillip and Westernport Catchment Management Authority, Resilient Melbourne, RMIT University, South East Water, The Nature Conservancy, and the University of Melbourne.

\section{REFERENCES}

[1] World Bank, World Bank Data, 2015, Online. http://data.worldbank.org/topic/urban development. Accessed on: 1 Mar. 2017.

[2] Bjorvatn, K., Urban infrastructure and industrialization. Journal of Urban Economics, 48(2), pp. 205-218, 2000.

[3] Malekpour, S., Brown, R.R. \& De Haan, F.J., Strategic planning of urban infrastructure for environmental sustainability: Understanding the past to intervene for the future. Cities, 46, pp. 67-75, 2015.

[4] Gaillard, J.-C., Vulnerability, capacity and resilience: perspectives for climate and development policy. Journal of International Development, 22(2), pp. 218-232, 2010.

[5] Infrastructure Australia, State of Australian cities 2010, Australian Government, Canberra, 2010.

[6] Badland, H., et al., Urban liveability: Emerging lessons from Australia for exploring the potential for indicators to measure the social determinants of health. Social Science \& Medicine, 111, pp. 64-73, 2014.

[7] Bowler, D.E., Buyung-Ali L. \& Knight, T.M., Urban greening to cool towns and cities: A systematic review of the empirical evidence. Landscape and Urban Planning, 97(3), pp. 147-155, 2010.

[8] James, E., Breen, P. \& Browne, D., Stormwater reuse to mitigate impacts from increased runoff frequency and volume, Barton, 2015.

[9] McDonald, R.I., Kareiva, P. \& Forman, R.T., The implications of current and future urbanization for global protected areas and biodiversity conservation. Biological Conservation, 141(6), pp. 1695-1703, 2008.

[10] Maller, C., Townsend, M., Pryor, A., Brown, P. \& St Leger, L., Healthy nature healthy people: Contact with nature as an upstream health promotion intervention for populations. Health Promotion International, 21(1), pp. 45-54, 2006.

[11] Hasunuma, H., Ishimaru, Y., Yoda, Y. \& Shima, M., Decline of ambient air pollution levels due to measures to control automobile emissions and effects on the prevalence of respiratory and allergic disorders among children in Japan. Environmental Research, 131, pp. 111-118, 2014.

[12] Manteghi, G., Bin Limit, H. \& Remaz, D., Water bodies an urban microclimate: A review. Modern Applied Science, 9(6), pp. 1-12, 2015.

[13] National Oceanic and Atmospheric Administration, Climate.gov, 2012, Online. https://www.climate.gov/news-features/understanding-climate/climate-changeglobal-temperature-projections. Accessed on: 2 Mar. 2017. 
[14] Coates, L., An overview of fatalities from some natural hazards in Australia, Australia, 1996.

[15] Green Surge, Green Infrastructure planning and implementation, 2015.

[16] Kendal, D., Lee, K., Ramalho, C., Bowen, K. \& Bush, J., Benefits of urban green space in the Australian context. Clean Air and Urban Landscapes Hub, Melbourne, 2016.

[17] Phelan, K. \& Hurley, J., Making greening happen in consolidating cities: Policy review. Clean Air and Urban Landscapes Hub, Melbourne, 2016.

[18] Brown, R.R., Keath, N. \& Wong, T.H.F., Urban water management in cities: Historical, current and future regimes. Water Science and Technology, 59(5), pp. 847-855, 2009.

[19] Furlong, C., De Silva, S., Guthrie, L. \& Considine, R., Developing a water infrastructure planning framework for the complex modern planning environment. Utilities Policy, 38, pp. 1-10, 2016.

[20] Furlong, C., De Silva, S., Gan, K., Guthrie, L. \& Considine, R., Risk management, financial evaluation and funding for wastewater and stormwater reuse projects. Journal of Environmental Management, 191, pp. 83-95, 2017.

[21] WSAA, The role of the urban water industry in contributing to liveability, WSAA, 2014.

[22] Furlong, C., Guthrie, L., De Silva, S. \& Considine, R., Analysing the terminology of integration in the water management field. Water Policy, 17, pp. 46-60, 2015.

[23] Furlong, C., De Silva, S. \& Guthrie, L., Planning scales and approval processes for IUWM infrastructure. Water Policy, 18, pp. 783-802, 2016.

[24] Brown, R.R. \& Clarke, J.M., Transition to Water Sensitive Urban Design: The Story of Melbourne, Australia, 1st ed., Facility for Advancing Water Biofiltration, Monash University: Melbourne, 2007.

[25] LeadWest, Western Agenda: A strategic action plan for Melbourne's western region 2008-2011, LeadWest, Melbourne, 2010.

[26] Institute for Sustainable Futures, Benchmarking Australia's Urban Tree Canopy: An i-Tree Assessment, Final Report, 2014.

[27] Resilient Melbourne, Resilient Melbourne Strategy, City of Melbourne, Melbourne, 2016.

[28] Daniel, C., Morrison, T.H. \& Phinn, S., The governance of private residential land in cities and spatial effects on tree cover. Environmental Science \& Policy, 62, pp. 79-89, 2016. 